\title{
Game-Based Didactic Resources as a Strategy in Foreign Language Pedagogy
}

\author{
Valeria Sumonte Rojas, Lidia Fuentealba Fuentealba and Ranjeeva Ranjan* \\ Faculty of Educational Sciences \\ Universidad Católica del Maule, Talca, Chile \\ https:// orcid.org/0000-0001-8873-1892 \\ https:// orcid.org/0000-0002-9908-2928 \\ https://orcid.org/0000-0002-7667-2191
}

\begin{abstract}
Gamification is a method widely used in recent years in the educational field to facilitate the teaching and learning process using different game elements and mechanics. The objective of this study was to analyze the use of non-digital game-based (NDGB) didactic resources as a strategy to facilitate the learning of Haitian Creole and its culture by native Chilean adult professionals. The study followed a qualitative approach, the design of which was a case study corresponding to the implementation of a Haitian Creole language-learning program. Sixty Chilean adult professionals participated, of which thirty-one belonged to the police department and twenty-nine to the local health department. These professionals have to help Haitian migrants who arrive in the country without the capacity to communicate in the target language, Spanish. The instruments used in this case study were participant classroom observation and a semi-structured interview, both implemented by the researchers. The results show that NDGB didactic resources facilitate language learning, favor situated work, and motivate learners to learn. In addition, it enables the co-construction of knowledge, based on collaborative work where all learners play a participatory role in the game. Participants showed greater commitment to language learning, those they have to attend to, and the needs of those they have to serve in their professional life.
\end{abstract}

Keywords: Chilean adult professionals; game-based learning; gamification; non-digital; strategy

\section{Introduction}

The theory of evolution proffered by Darwin in the 19th century is as true for the human species as it is for languages. The field of education and language

\footnotetext{
*Corresponding author: Ranjeeva Ranjan; ranjan@ucm.cl
} 
education, in particular, is constantly evolving to cope with the upheavals brought by globalization at individual and professional levels. The chain of current events, such as technological access, the COVID-19 pandemic, and migration, demands responses to different challenges that each of these events brings to society. Migration is experienced globally. It refers to the number of individuals living in countries other than that of their birth or origin. According to the United Nations Organization (UNO, 2019), this number stands at 272 million people in the world.

Chile also experiences the reality of migration (UNO, 2019). Out of a population of 19 in 2016 million, 2.7\% were migrants (CASEN, 2016). This number has increased significantly in a few years, reaching $8.3 \%$ at present, corresponding to $1,492,522$ individuals, according to the National Institute of Statistics and Department of Foreigners and Migration (NIS \& DFM, 2020). Most of the migrants are from Venezuela $(455,494)$, Peru $(235,165)$, and Haiti $(185,865)$. Even though Haitians are the smallest of these three groups, they are the group that brings the greatest challenges in the Chilean context in terms of the learning and teaching of the second language.

The majority of Haitian migrants are adults (92.93\%) (Table 1$)$. They speak Haitian Creole, which means that they do not possess the language skills to communicate with the receiving community. Furthermore, Haitian Creole is spoken by a minority who live in Chile in vulnerable conditions (Sumonte, 2020).

Table 1: Haitian migrants by age and gender

\begin{tabular}{llll}
\hline Age range & Male & Female & Total \\
\hline $0-19$ years & 6,317 & 6,819 & 13,136 \\
20-onwards & 112,751 & 59,978 & 172,729 \\
Total & 119,068 & 66,797 & 185,865 \\
\hline
\end{tabular}

Haiti was a French colony inhabited by slaves who attained freedom in 1804 . As such, the Haitian State became the first country on the continent to become independent. Since its discovery in the 15th century and its subsequent independence, Haiti has had to overcome different events of violence, political and economic instability, as well as natural disasters. Regarding the violence and political instability, it is notable that around 80 presidents have ruled the country up to date and most of them have ended their mandate irregularly. Some were assassinated, others fled the country (Jaramillo \& Sancak, 2007), and some had to endure natural disasters such as floods, droughts, tsunamis, and earthquakes.

Regarding the economic sphere, considering the Gini coefficient, ${ }^{t}$ the standard measure used to establish the differences in income between the poorest and the richest, the numbers yield a 0.61 level of inequality (Ceara-Hatton, 2017). In 2012, the official poverty rate in Haiti was $58.7 \%$ and the extreme poverty rate was

${ }^{+}$The Gini coefficient is a statistical measure of the degree of variation represented in a set of values, used to analyze income inequality, going from 1 to 0 , with 0 being the perfect equality and 1 expressing maximal inequality. 
$23.9 \%$. Subsequently, Haiti's history offers sufficient proof as to why Haitians are migrating. The events that have occurred from the discovery of the island to the present, namely political instability and social and economic problems owing to an elite concerned with their own interests, have left citizens with no choice but to migrate.

In order to favor Haitian inclusion in the Chilean context, an educational program for teaching and learning Haitian Creole by Chilean police officers and health care professionals was developed. These professionals are adults from two governmental entities who have direct contact with the different migratory groups. Nevertheless, these professionals have been unable to provide quality care to the migrant group from Haiti because of communication challenges owing to language barriers from both sides. Consequently, we designed a set of didactic resources as a non-digital game-based (NDGB) strategy to be used with the professionals in order to facilitate the teaching and learning of Haitian Creole.

As such, the objective of this study was to analyze the use of NDGB didactic resources as a strategy to facilitate the learning of Haitian Creole and its culture by adult native Chilean professionals. The study tries to fill the gap by advancing the theoretical knowledge base and making academic developments within the second language acquisition (SLA) domain by looking at learners' perception of gamification and its effects on language learning in adult professionals. It also provides empirical evidence on how adult foreign language learners perceive the use of NDGB didactic resources.

Most of the literature on gamification and game-based learning (GBL) focuses on digital games in the educational process. However, non-digital games as learning tools have not received sufficient consideration owing to little intellectual corpus being available on this topic (Alfallaj, 2020), and this is a gap considered in this work. In some studies, some comparisons associated with these two types of games have been made. Petri et al. (2018) reported that both digital and non-digital games have contributed positively to students' learning; however, non-digital games have been shown to yield better achievement of learning objectives. Alfallaj (2020) recommended that for meeting efficient learning needs, there should be a collaborative effort between language educators and learners for designing non-digital games. Using this type of game is advantageous in that it provides face-to-face communication incorporating different forms of learning, such as reading, chatting, seminars, tasks, community activities, video clips, and presentations (Alfallaj, 2020). However, there is a lacuna in the research in the area of the usage of non-digital games as learning tools in the foreign language classroom, which the present study wants to fill.

\section{Literature Review}

This section presents a brief discussion of the theoretical framework encompassing the concepts of gamification, GBL, and its role in the educational context. 


\subsection{Gamification and Educational Context}

The term "gamification" was coined at the beginning of the 21st century and its first documented use dates back to 2008 (Deterding et al., 2011). Gamification is a key concept that has attracted attention and holds significance in academia and practice, especially in education (Manzano-León et al., 2021; Sailer \& Homner, 2020), and has turned out to be a subject of interest for educational researchers (Swacha, 2021). Earlier, this concept was used in business to refer to the application of game elements in order to attract, encourage, and persuade users to perform a certain action. The concept of gamification is quite complex and related to applied fields of business, management, and education, among other fields. Deterding et al.'s (2011) definition of this concept as "the use of game design elements in non-game contexts" (p. 9) is perhaps a bit simple. The academic world has been interested in this area, with education being among the top fields conducting gamification research (Dichev \& Dicheva, 2017; Sailer \& Homner, 2020; Seaborn \& Fels, 2015). Kapp (2012) provided a more comprehensive definition of this concept, describing it as the use of "game-based mechanics, aesthetics and game thinking to engage people, motivate action, promote learning, and solve problems" (p. 10). Thus, gamification may be considered as the application of game principles and elements in a learning environment to influence behavior, increase motivation, and encourage student participation.

Gamification, as a concept, has positive outcomes that have been investigated thoroughly in various fields both "conceptually and empirically" (Dehghanzadeh et al., 2019). In the context of English as a second/foreign language, gamification has been seen as one strategy to engage learners (Huang et al., 2019; Landers \& Landers, 2014; Tan \& Hew, 2016), to motivate them (Ghasemi et al., 2017), to influence the learning outcomes (Tan \& Hew, 2016), and to help in facilitating collaborative learning (Buckley \& Doyle, 2014). In their quasi-experimental research, Lukas et al. (2020) established the potential of educational games as a strategy to enhance learners' memory retention and promote learning motivation. They highlighted the use of games in creating more interesting, useful, and meaningful teaching. In another study, Idris et al. (2020) underlined the effectiveness of Kahoot, a GBL platform used to reinforce English grammar to learners. The researchers concluded that gamification, through its captivating features, facilitated reducing the learners' affective filter when learning grammar and then enhancing their motivation. Ni et al. (2020) stated that educational games help in improving cooperation, collaboration, communication, creativity, and critical thinking skills among students. This research also highlighted the potential use of games in English as a second language (ESL) classrooms for better memory retention of the vocabulary learned. Muntean (2011) pointed out that gamification allows learner engagement through the use of extrinsic elements such as levels, points, and badges and promotes intrinsic motivation by generating appreciation of one's mastery, autonomy, and connectedness.

The advantages of gamification have been researched and explained under the theoretical framework of motivation, engagement, and psychology (Le, 2020). The theory of self-determination (SDT) embodies a broad framework studying human motivation and personality (Ryan \& Deci, 2020). SDT articulates a meta-theory for 
explaining the intrinsic and extrinsic sources of motivation and their roles in cognitive and social development in individual differences (Ryan \& Deci, 2020). The theory encompasses three important psychological elements of human motivation: autonomy, competence, and relatedness. Autonomy refers to "a sense of initiative and ownership in one's actions" (Ryan \& Deci, 2020, p. 1), which is weakened by experiences of external control. Competence, in this context, concerns the feeling of mastery that "afford[s] optimal challenges, positive feedback, and opportunities for growth" (Ryan \& Deci, 2020, p. 1). Finally, relatedness is seen as a "sense of belonging and connection" (Ryan \& Deci, 2020, p. 1). In a way, this may also lead to the collaborative effort in learning. These elements are important to comprehend "the what (content) and why (process) of goal pursuit and goal-directed behaviour" (Deci \& Ryan, 2000; Ryan \& Deci. 2000).

\subsection{Gamification vs Game-Based Learning}

The real value of game-based mechanics is to create meaningful learning experiences (Kapp, 2012). Wiggins (2016) offered two scenarios in trying to distinguish between gamification and GBL. In the first, gamification is included under the umbrella term of GBL, whereas in the second, these terms are used distinctly. In the first case, Wiggins (2016) referred to gamification as a "re-imagination of traditional educational strategies" (p. 19) employed to infuse both extrinsic and intrinsic motivation within the learner. In the latter, GBL may be defined as "the use of games (digital or non-digital) in educational contexts as a part of a learning objective" (Wiggins, 2016). In many instances, these two terms have been used interchangeably, referring to the same idea (Callaghan et al., 2013; Epper et al., 2012).

\subsection{Collaborative Learning}

Chandra's (2015) understanding of collaborative learning is that "collaboration is a way of interaction and personal attitude where individuals are responsible for their own actions, learning, their abilities and contributions of their peers as well" (p. 1). The same author further stated that collaborative activities are based on the learner being at the center of instruction and interaction and that groupwork is essential for learning to occur.

Vygotsky (1997) established that through dialogical and collaborative work, learners reformulate a problem and then search for and develop a possible solution. What thus begins as a collective task can be transformed by the learner into a task to be individually comprehended. Even more, Vygotsky (1997) stated that from a sociocultural perspective, if the acquisition of new concepts arises from a given context, they tend to be more meaningful for learners.

Subsequently, learning is socially constructed by the simple act of interacting and carrying out activities with others collaboratively. It offers opportunities to (re)construct one's own models of reasoning and ways of thinking, and to develop problem-solving strategies according to the conceptions gathered by those with whom one interacts.

Mitchell and Myles (2004) noted that a learner learns a language to the extent that it is meaningful to them, which is possible through the collaboration of others who 
belong to the culture that encompasses the second language being learned. According to Sumonte et al. (2019), collaborative learning is understood as equal interaction of participants when learning another language. As such, contributors collectively build intercultural knowledge through the exchange of experiences in a specific context. This context becomes the space where interaction takes place, where those who participate in each educational encounter negotiate meanings, and where whoever guides each encounter provides opportunities for the conscious construction of knowledge. The relevance of the context is an element that makes such knowledge concrete, practical, and applicable.

\subsection{Interculturality}

According to Dietz (2018), the concept of interculturality is used to refer to the relationships that exist between people who are culturally diverse, as related to their ethnicity, culture, language, and religion, among other constructs. Interculturality is not only about accepting others but also about understanding their way of seeing the world (González-Alonso, 2019). In this sense, migratory groups bring ethnocultural characteristics and diverse languages with them. Therefore, for an inclusive society respectful of diversity, the goal is not only to learn the linguistic elements of the second/foreign language but also to move towards developing the establishment of human skills that facilitate the construction of a horizontal dialogue avoiding monocultural educational and social practices. This inclusion is configured as a dynamic process of reciprocal rapprochement and empathy, which involves the recognition of the differences and similarities of the other (Torres, 2002, cited in Barrios-Valenzuela \& PalouJulián, 2014, p. 409). For their part, Rojas Pedemonte and Koechlin (2017) pointed out that it is necessary to favor intercultural coexistence environments that benefit the psychological well-being of all members of the community. For this to happen, these members must recognize the cultural richness of the other. Likewise, diversity constitutes a valuable component that enriches the community, but at the same time poses multidimensional challenges, one of these being related to mutual understanding using a common language and cultural recognition.

Research on language learning and the development of intercultural competencies that facilitate the inclusion of non-digital GBL in a foreign language learning (FLL) program is almost unexplored. Therefore, the implementation of GBL as an FLL strategy in the classroom activities would motivate and stimulate learners to develop competencies in the use of a foreign language as well as collaborative work and intercultural exchange.

\subsection{General Objective and Research Questions}

The objective of the current study is to analyze the use of NDGB didactic resources as a strategy to facilitate the learning of Haitian Creole and its culture in adult native Spanish-speaking professionals.

The present study aims to respond to the following research questions:

- RQ1. What are Chilean adult professionals' perception of using NDGB didactic resources in their learning trajectory of Haitian Creole as a foreign language? 
- RQ2. How do NDGB didactic resources facilitate collaborative work among adult Haitian Creole learners?

- RQ3. How does a NDGB strategy facilitate the intercultural acquisition process of Chilean adult professionals who are learning Haitian Creole as a foreign language?

\section{Methodology}

This research was developed under a qualitative paradigm of the non-experimental type. We examined Chilean adult professionals' perceptions on the use of NDGB didactic resources in their FLL process, as well as how these resources facilitate the collaborative and intercultural learning of the participants. Qualitative researchers investigate natural and inductive processes with the purpose to describe multiple realities to deeply understand the object under study. In this case, learners' discourses and their behavior while learning a foreign language using non-digital games were analyzed. The games used were bingo, scattergories, role-playing, mimicry, and card games.

\subsection{Participants of the Study}

The participants $(\mathrm{N}=60)$ of the study comprised two groups of adult professionals. One group comprised police officers $(n=31)$ and the other health care professionals $(n=29)$. The non-probabilistic sample of convenience was composed of $51.6 \%$ women and $48.4 \%$ men, giving the sample a homogeneous character. The participants' age varied from 28 to 60 years. In Chile, these two groups of professionals are motivated to learn Haitian Creole to facilitate communication with Haitian migrants who do not possess Spanish-speaking skills. Haitian migrants visit the offices of police officers to legalize the documents that allow them to stay in the country and, at the same time, to start being part of the society. Nevertheless, when there is misunderstanding because of the language barrier, migrants retain their illegal status. Haitian migrants also attend Chilean health care institutions when they have health problems. Doctors and nurses find it hard to comprehend the health problems of these migrants because of language barriers and cultural differences. These two obstacles have had as consequence the death of some of these migrants.

\subsection{Instruments Used}

The data collection tools used in this study are a semi-structured interview and participant observation. Both instruments, developed by us, underwent a content validity process, with a score of 0.8 , and a methodological design proposed by Galicia Alarcón et al. (2017). This validation includes three evaluation categories: clarity, coherence, and relevance. Experts from different areas of expertise validated both instruments. Two experts were from the second/foreign language learning area, one was an English teacher from a teaching training program, and one was an expert in research methodology. The kappa statistic (к) was used to test interrater reliability, which was calculated to be 0.92 .

For applying both instruments, a protocol was developed to consider ethical aspects, with informed consent signed by the participants. Both data collection tools focused on the participants' perception of using game-based didactic 
resources in their Haitian Creole learning, as well as on how this strategy facilitates collaboration, motivation, and comprehension of the target language. Participant observation was employed once a week during the Haitian Creole language-learning program. This program ran for three months, twice a week. The duration of each session was one and a half hours. Interviews were carried out 15 days after the completion of the program as per the participants' availability. The interviews were transcribed and thereafter analyzed by each researcher separately using the NVivo 10 program to validate the results obtained. The information was codified to identify the number of the question asked; for example, Q10 means question number 10. In the same way, the field notes during participant observation were codified as FN and the week as W.

\section{Results and Discussion of the Study}

As has been said previously, research on gamification has demonstrated its positive impact on learners. It engages learners in their learning tasks (Huang et al., 2019; Landers \& Landers, 2014; Tan \& Hew, 2016), motivates them (Ghasemi et al., 2017), favors their learning outcomes (Tan \& Hew, 2016), helps in facilitating collaboration (Buckley \& Doyle, 2014), and enhances learners' memory retention (Lukas et al., 2020). The current work also verifies these positive impacts. By analyzing participants' discourses extracted from their responses to the semi-structured interview and participant observation, we respond in this section to the three research questions raised in this paper.

\subsection{Professionals' Perceptions of Using Non-Digital Game-Based Didactic Resources}

The first research question deals with the implementation of NDGB didactic resources and the participants' perception of their learning using this methodology. One of the participants mentioned that:

“(...) I really liked the methodology implemented in this course (...), the games were something different. I found it very entertaining; we moved around the room; we were not always seated." (Q2)

Gamification is not a new resource used in education and seeks to enrich students' learning. Research in this area is far from being completed, as the strategy has high potential strategy to be implemented (Surendeleg et al., 2014). The group of participants noted they had participated in several training courses, although this one was different from all the others. None of them had used a GBL approach before. Rather, the class methodology comprised mainly theoretical work, memorization, and no movement; they had to sit down during the whole course. One of the participants stated:

"When different courses are given (...) everyone is seated; it is not in a group, you do not move, only the teacher talks (...), but the method of this course strengthens the connections between students. I did not know some colleagues who are working in other clinics (...). The methodology is entertaining." (Q2)

All the participants agreed that the games used in class were entertaining and dynamic, and they felt that they were motivated to think and be attentive to the content developed in the class. We can say that this confirms the purpose of 
gamification; it is not for enjoyment, but rather favors motivation, engagement, and user experience (Bencsik et al., 2021). The dynamics made it easier to remember the content when they had to apply it outside the classroom, in their workplace, where they were confronted with Haitian migrants without any knowledge of Spanish. Surendeleg et al. (2014) mentioned some studies that have discovered that knowledge can be deeply absorbed through gamification and also include not only young people but also adults.

The different games allowed for various contents to be learned using several dynamics. For example, cards were used to learn vocabulary. In this game, participants were shown a printed word on a card, and if they knew its meaning, had to run to take it and make a sentence using that word on a whiteboard. The participant who constructed the sentence correctly received a score, which would be part of their evaluations. Regarding this exercise, one participant responded:

"For example, when we worked with the cards, we had to run out and make a sentence, so we all had to make a sentence." (Q2)

Mimicry is mainly structured to facilitate the learning of actions (verbs). Participants who guessed the action represented through mimicry had to stand up from their seat, verbalize the action, and perform it themselves. The participant then had to choose a classmate for the next representation. Regarding this game, a participant stated:

"The verbs are always difficult, but mimicry helped me to understand them because, later, in the evaluation or when I had to use them at work, I tried to remember the game and it allowed me to make the relationship between the mime and the verb." (Q6)

Another game used for learning was bingo (Figure 1), whose objective is to connect the number mentioned orally with its respective number on a cardboard card. First, participants had to listen to a number read out by the teacher. Then, they had to mark it on their cards and repeat the number. This game involved three levels: first, the one who completed one line of five numbers on the cardboard card, then two lines, and finally, the one who completed all the numbers. For each level, the participant who achieved that level first was rewarded with an object (Figure 1).

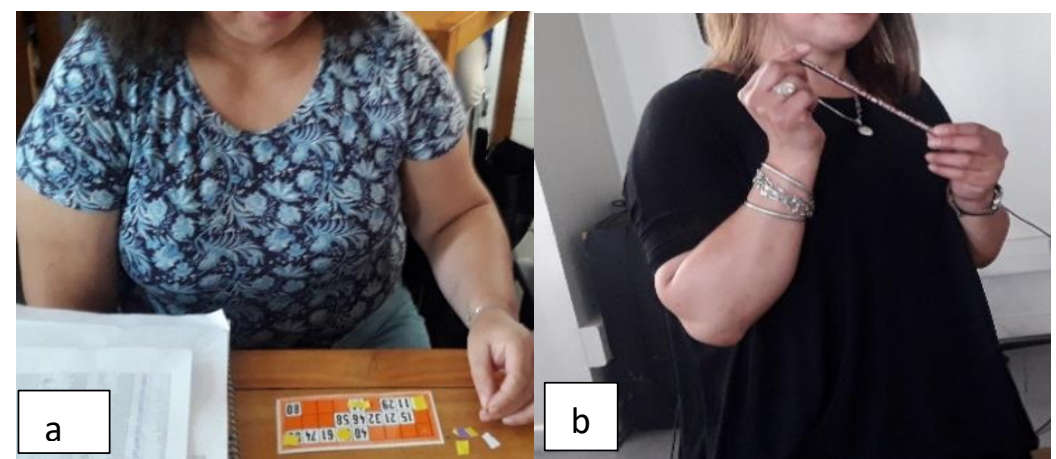

Figure 1: a) Playing bingo and b) receiving a reward after finishing the task (W2) 


\subsection{Collaborative Work through the Non-Digital Game-Based Didactic Resources}

Collaborative work and the joint construction of intercultural knowledge are favored among students based on their knowledge in the process of learning. This involves the development of linguistic competencies of the foreign language by employing games. In this context, each participant is responsible for their learning, but at the same time is part of the learning of the other. According to Hiltz and Turoff (1993), collaborative learning can be defined as a process that favors group or cooperative efforts among teachers and students. They further added that in this process of collaborative learning, knowledge is seen as a social development, which facilitates the educational process in an environment, which assists peer interaction, evaluation, and cooperation.

Interaction enriches the learning process because it allows learners to experience different starting points (Bencsik et al., 2021). Therefore, learning occurs by collaborating with each other and placing individuals' own understanding at the service of others. In these tasks, all participants worked as a team to accomplish the same objectives, contributing from their own expertise. Currently, considering the diverse daily cultural reality, social contexts call for didactic strategies directed to favor interactive situations (Barrera Vázquez \& Cabrera Albert, 2021). In this case, learners understand that each one has certain knowledge that can be shared allowing them to achieve the objective. Regarding this, one of the participants stated:

"We got together to study, and we were willing to do it, to review; each one contributed what we knew to finish the task." (Q5)

According to the Vygotskian view, "learners appropriate cultural practices and tools through interaction with more experienced members" (Díaz, 2003, p. 3). This was noticed in the following observation during a class.

"When groups of five to seven members must be formed to solve assigned tasks, each participant contributes his or her knowledge to achieve the objective. During this process, it is observed that everyone contributes and complements each other until the work is completed." (FN, W4)

An example of this is scattergories (Figure 2). In this game, groups are formed, standing in front of a whiteboard. They choose someone to write a word using a given letter. The rest of the group helps to find the word that has that letter. The first one to write the word receives extra credits for the whole group. The enhancement of this type of context promotes participation in the learning activities because of the opportunities to collaborate, which means more chances to achieve the assignment. 


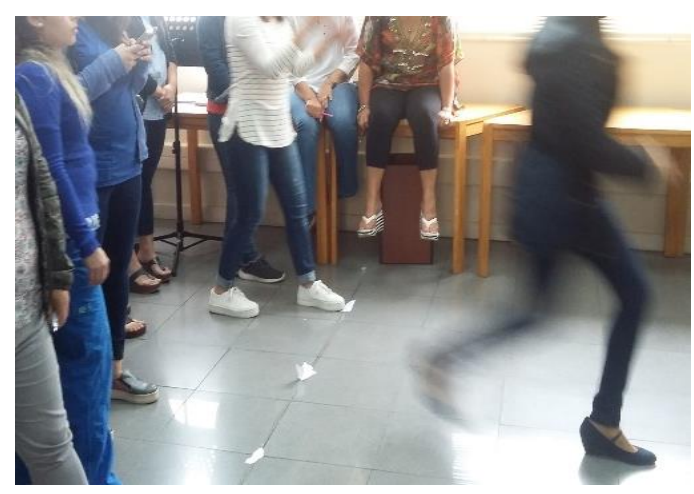

Figure 2. Collaborative learning by using scattergories (W4)

Vygotsky (1997) pointed out that dialogic and collaborative work allows learners to reformulate a problem and search for and develop a possible solution. In this case, the game that begins as a collective task allows the internalization of the language initiated from the knowledge common to all and then applied in the professional environment individually. From this perspective, learners develop, as a group, the construction of knowledge, which constitutes both collective and individual knowledge (Wink \& Putney, 2002).

\subsection{Intercultural Acquisition through Non-Digital Games}

At the beginning of the Haitian Creole language-learning program, games were used for learning language in a concrete manner. After a while, these games were used in a non-concrete manner to build cultural awareness and knowledge exchange among participants.

For example, one of the contents was to learn the days of the week. For this purpose, seven different cards, each with a day of the week, were displayed. When reaching Sunday, the instructor in the classroom asked what was done in Chile on a Sunday, because Sunday is a religious day for Haitians. In this case, the concrete element (the card) allows sharing a cultural aspect that is not concrete. We made the following observation regarding this:

"The days of the week are taught. Cards with each day are shown; students work in groups of seven people, each reading one day. By the time they get to Sunday, a Haitian person in the classroom asks what they do in Chile on Sundays. At this point, the group stops and begins to share what Chileans and Haitians do on Sundays in their respective countries." (FN, W2)

The cultural-knowledge exchange allows students to represent their worldview through the learning of a language. It could also be explained from the affective dimension of intercultural communication which implies establishing relationships with interlocutors whose cultural referents differ from each other (Chen \& Starosta, 1998). In this context, it is important to consider including cultural aspects when working on a foreign/ second language-learning program. Regarding this, a participant stated:

"All of this is also important (...) to know their country, their language; we got to know them, what they do, their family, what they like; we 
comprehend better how they understand things, we get to know their culture." (Q5)

The instructors who led each session of the program were native speakers of Haitian Creole. The teaching of native speakers may favor what Mitchell and Myles (2004) pointed out, that a language is learned to the extent that it is meaningful to the learner. In this case, the interaction between the participants and the native speakers who were willing to answer all their questions regarding the use of the language may possibly be a plus. These instructors also facilitate the development of activities using role-play, where Chilean learners and instructors use real situations of both countries to practice the language and understand how to deal with these situations in both cultures. Blatner (2009) pointed out that roleplaying is a strategy that facilitates the development of skills such as taking initiative, communication, problem solving, confidence, and teamwork. Likewise, it offers the student the possibility of personifying or simulating real situations about the cultural differences, values, and beliefs of the citizens of both countries. The student uses Haitian Creole, on the one hand, and comprehends their ways of understanding reality, on the other. One of the participants stated:

"The role-play is one of the activities that I liked the most, since we were able to imitate, for example, how to face a Haitian couple when they go to the doctor's office, with the differences and similarities with our own ways of acting." (Q4)

Regarding couples, the Chilean participants highlighted the differences between the way in which men and women relate to each other as a couple. The conversation led to them concluding that Haiti has what they considered a male-dominated culture. Accordingly, Lamour (2021) stated that Haitian society is sexist. One participant pointed out that:

"I liked learning about their culture. I considered them a macho society. A few days ago, a couple came to be seen, and I told her to sit down, but he sat down - that bothered me. Now, I understand that it is part of them, that it is their way of understanding each other and it is part of their culture." (Q11)

The participants' discourses demonstrate a favorable perception of the use of non-digital games in that it facilitates the acquisition of the target language, promotes collaborative work, and develops intercultural componence. The favorable perception is achieved because the focus of learning is on how it is learned (Manca et al., 2019). In this regard, second/foreign language learning processes address not only external factors but also psychological ones (Ranjan \& Philominraj, 2020). Therefore, learning in this type of context with the use of GBL provides opportunities to enhance learner commitment in language acquisition. These types of student-centered teaching methodologies provide meaningful learning (Philominraj et al., 2021) and ensure greater success in language learning.

\section{Conclusion}

This paper introduced and analyzed the use of NDGB didactic resources as a strategy and learning approach for learning a foreign language spoken by a minority group. In this sense, the study could successfully achieve its main 
objective and respond to the research questions raised. The research study highlighted that NDGB didactic resources can serve as a useful strategy to learn a language. It allows the student to be engaged in the activities, resulting in active participation in their own learning and that of their peers. In the same line, both types of motivation (intrinsic and extrinsic) could be identified in this research. The participants were first extrinsically interested in communicating using Haitian Creole because they needed to offer qualified assistance. Nevertheless, learning the language and at the same time its culture through a gamified context allowed them to develop intrinsic motivation by showing their interest in continuing their learning beyond the end of the program. GBL strategy supports educational processes. This strategy is at the learning service and not the other way around. Hence, learning experiences should be designed considering the elements of a game. The study was limited to two groups of professionals; we therefore propose the inclusion of other groups and younger people for further study. Based on the findings of the research, we recommend a systematic teacher-training program and continuous development in using NDGB didactic resources to enhance learners' engagement and motivation.

\section{Funding}

The research was sponsored by the Fondecyt of Initiation Project $N^{\circ} 11190448$ National Research and Development Agency - ANID and by the Advanced Human Capital Training Program CONICYT N² 21182041, both from Chile.

\section{Acknowledgments}

We would like to express our cordial thanks to all the participants, who voluntarily took part in this study.

\section{Conflict of Interest}

The authors declare no conflict of interest.

\section{References}

Alfallaj, F. S. S. (2020). Non-digital gamification of the English as foreign language classroom: Developing the tools at home. The Asian ESP Journal, 16(5.2), 131-152.

Barrera Vázquez, S., \& Cabrera Albert, J. S. (2021). Culture, interculturality and education: Referents of the teaching-learning of foreign cultures. MENDIVE, 19(3), 999-1013. https:// mendive.upr.edu.cu/index.php/MendiveUPR/article/view/2380

Barrios-Valenzuela, L A., \& Palou-Julián, B. (2014). Educación intercultural en Chile: La integración del alumnado extranjero en el sistema escolar [Intercultural education in Chile: The integration of foreign students in the school system]. Educación $y$ Educadores, 17(3), 405-426. https:/ / doi.org/10.5294/edu.2014.17.3.1

Bencsik, A., Mezeiova, A., \& Oszene Samu, B. (2021). Gamification in higher education (Case study on a management subject). International Journal of Learning, Teaching and Educational Research, 20(5), 211-231. https://doi.org/10.26803/ijlter.20.5.12

Blatner, A. (2009). Role playing in education. https://www.blatner.com/adam/pdntbk/rlplayedu.htm

Buckley, P., \& Doyle, E. (2014). Gamification and student motivation. Interactive Learning Environments, 24, 1162-1175. https:/ / doi.org/10.1080/10494820.2014.964263

Callaghan, M. J., McCusker, K., Losada, J. L., Harkin, J., \& Wilson, S. (2013). Using gamebased learning in virtual worlds to teach electronic and electrical engineering. 
IEEE Transactions on Industrial Informatics, 9(1), 575-584. https://doi.org/10.1109/TII.2012.2221133

CASEN. (2016). Encuesta de caracterización socioeconómica nacional [National socioeconomic characterization survey]. Governmentof Chile.

Ceara-Hatton, M. (2017). Haití y República Dominicana: Divergencia, población y migración [Haiti and the Dominican Republic: Divergence, population and migration]. Ciencias de la Administración, Económicas y Jurídicas, 1(2), 10-27. http:/ / hdl.handle.net/20.500.12060/1798

Chandra, R. (2015). Collaborative learning for educational achievement. IOSR Journal of Research E Method in Education (IOSR-JRME), 5(2), 4-7. https://www.researchgate.net/publication/313889863_Collaborative_Learning _for_Educational_Achievement

Chen, G-M., \& Starosta, W. J. (1998). Foundations of intercultural communication. Allyn and Bacon.

Deci, E. L., \& Ryan, R. M. (2000). The "what" and "why" of goal pursuits: Human needs and the self-determination of behavior. Psychological Inquiry, 11(4), 227-268. https://doi.org/10.1207/S15327965PLI1104_01

Dehghanzadeh, H., Fardanesh, H., Hatami, J., Talaee, E., \& Noroozi, O. (2019). Using gamification to support learning English as a second language: A systematic review. Computer Assisted Language Learning, 34(7), 934-957. https://doi.org/10.1080/09588221.2019.1648298

Deterding, S., Dixon, D., Khaled, R., \& Nacke, L. (2011). From game design elements to gamefulness: Defining "gamification". In Proceedings of the 15th International Academic MindTrek Conference: Envisioning future media environments, 7, 9-15. https://doi.org/10.1145/2181037.2181040

Díaz, F. (2003). Cognición situada y estrategias para el aprendizaje significativo [Situated cognition and strategies for meaningful learning]. Revista Electrónica de Investigación Educativa, 5(2), 1-13.

http:/ / www.scielo.org.mx/scielo.php?script=sci_arttext\&pid=S160740412003000200011

Dichev, C., \& Dicheva, D. (2017) Gamifying education: What is known, what is believed and what remains uncertain: A critical review. International Journal of Educational Technolology in Higher Education, 14(9), 1-36. https:/ / doi.org/10.1186/s41239-0170042-5

Dietz, G. (2018). Interculturality. In H. Callan (Ed.), The international encyclopedia of anthropology. John Wiley \& Sons. https://doi.org/10.1002/9781118924396.wbiea1629

Epper, R. M., Derryberry, A., \& Jackson, S. (2012). Game-based learning: Developing an institutional strategy. EDUCAUSE Center for Analysis and Research. https://library.educause.edu/-/media/files/library/2012/8/erb1208-pdf.pdf

Galicia Alarcón, L., Balderrama Trápaga, J., \& Edel Navarro, R. (2017). Validez de contenido por juicio de expertos: Propuesta de una herramienta virtual [Content validity by expert judgment: Proposal of a virtual tool]. Apertura, 9(2), 42-53. http://dx.doi.org/10.18381/Ap.v9n2.993

Ghasemi, M., Jafari, S., \& Izadpanah, S. (2017). The effect of gamified program strategy on the learners' motivation. Journal of Applied Linguistics and Language Research, 4, 292-299.

González-Alonso, F. (2019). La educación intercultural en un taller de gamificación [Intercultural education in a gamification workshop]. In J. M. Hernández Díaz, A. Pozzer, \& E. Cecchetti (Eds.), Migración, interculturalidad y educación: Impactos y desafios [Migration, interculturality and education: Impacts and challenges] (pp. 827-861). Ediciones Universidad de Salamanca y Chapecó (Brasil): Argos Ediciones de U. 
Hiltz, S., \& Turoff, M. (1993). Video plus virtual classroom for distance education: Experience with graduate courses (invited paper). Conference on Distance Education in DoD, National Defense University, USA. http://penta.ufrgs.br/edu/telelab/12/dised2.htm

Huang, B., Hew, K. F., \& Lo, C. K. (2019). Investigating the effects of gamification-enhanced flipped learning on undergraduate students' behavioral and cognitive engagement. Interactive Learning Environments, 27, 1106-1126. https://doi.org/10.1080/10494820.2018.1495653

Idris, M. I., Mohd Said, N. E., \& Tan, K. H. (2020). Game-based learning platform and its effects on present tense mastery: Evidence from an ESL classroom. International Journal of Learning, Teaching and Educational Research, 19(5), 13-26. https:// doi.org/10.26803/ijlter.19.5.2

Jaramillo, L., \& Sancak, C. (2007). Growth in the Dominican Republic and Haiti: Why has the grass been greener on one side of Hispaniola? IMF Working Paper, 7(63), 1-35. https://www.imf.org/en/Publications/WP/Issues/2016/12/31/Growth-inthe-Dominican-Republic-and-Haiti-Why-has-the-Grass-Been-Greener-on-OneSide-of-20520

Kapp, K. M. (2012). The gamification of learning and instruction: Game-based methods and strategies for training and education. Pfeiffer.

Lamour, S. (2021). The toxic masculinity of the "Legal Bandit". NACLA Report on the Americas, 53(1), 88-93. https:// doi.org/10.1080/10714839.2021.1891649

Landers, R. N., \& Landers, A. K. (2014). An empirical test of the theory of gamified learning: The effect of leaderboards on time-on-task and academic performance. Simulation \& Gaming, 45(6), 769-785. https:// doi.org/10.1177/1046878114563662

Le, L. (2020). A real game-changer in ESL classroom? Boosting Vietnamese learner engagement with gamification. Computer-Assisted Language Learning Electronic Journal, 21, 198-212. http://callej.org/journal/21-3/Le-L2020.pdf

Lukas, B. A., Patrick, F. I. A., Chong, G., Jaino, N. B., \& Yunus, M. M. (2020). Using U-NO-ME card game to enhance primary one pupils' vocabulary. International Journal of Learning, Teaching and Educational Research, 19(5), 304-317. https://doi.org/10.26803/ijlter.19.5.19

Manca, R., Callai, S., Concas, R., Dessi, S. M., \& Fadda, L. (2019). Italian experiences in game-based learning and gamification methodologies in order to enhance student learning and teacher professional skills. In B. D. da Silva, J. A. Lencastre, M. Bento, \& A. J. Osório (Eds.), Experiences and perceptions of pedagogical practices with game-based learning \& gamification (pp. 57-65). Research Centre on Education (CIEd).

Manzano-León, A., Camacho-Lazarraga, P., Guerrero, M. A., Guerrero-Puerta, L., Aguilar-Parra, J. M., Trigueros, R., \& Alias, A. (2021). Between level up and game over: A systematic literature review of gamification in education. Sustainability, 13(4), 2247. https://doi.org/10.3390/su13042247

Mitchell, R., \& Myles, F. (2004). Second language learning theories. Arnold Ed.

Muntean, C. I. (2011). Raising engagement in e-learning through gamification. Proceedings of 6th International Conference on Virtual Learning ICVL, 1, 323-329. http://icvl.eu/2011/disc/icvl/documente/pdf/met/ICVL_ModelsAndMethod ologies_paper42.pdf

National Institute of Statistics and Department of Foreigners and Migration (NIS \& DFM). (2020). Demografía: Estimación población extranjera en Chile 2019 regiones y comunas síntesis 2020 [Demography: Estimated foreign population in Chile 2019 regions and communes synthesis 2020].

https://www.ine.cl/estadisticas/sociales/demografia-y-vitales/demografia-ymigracion/2020/05/21/d\%C3\% ADa-mundial-de-la-diversidad-cultural-

c\%C3\%B3mo-son-y-d\%C3\%B3nde-viven-los-migrantes-internacionales-en-chile

http://ijlter.org/index.php/ijlter 
Ni, C. K., Jong, B., Dison, M. A., Thomas, S. A.,Yunus, M. M., \& Suliman, A. (2020). Enhancing Malaysian primary pupils' vocabulary skills using pocable game and pear deck. International Journal of Learning, Teaching and Educational Research, 19(6), 145-160. https:// doi.org/10.26803/ijlter.19.6.9

Petri, G., Calderón, A., Von Wangenheim, C. G., Borgatto, A. F., \& Ruiz, M. (2018). Games for teaching software project management: An analysis of the benefits of digital and non-digital games. Journal of Universal Computer Science, 24(10), 1424-1451. https://doi.org/10.3217/jucs-024-10-1424

Philominraj, A., Ranjan, R., Saavedra, R. A., \& Urzúa C. A. C. (2021). English as foreign language teaching in high schools: A Chilean case study. International Journal of Learning, Teaching and Educational Research, 20(3), 51-67. https://doi.org/10.26803/ijlter.20.3.4

Ranjan, R., \& Philominraj, A. (2020). Language learning strategies, motivation and gender in foreign language context. Universal Journal of Educational Research, 8(2), 591-604. https://doi.org/10.13189/ujer.2020.080231

Rojas Pedemonte, N., \& Koechlin, J. (2017). Migración Haitiana hacia el sur andino [Haitian migration to the southern Andean region]. Litho \& Arte S.A.C.

Ryan, R. M., \& Deci, E. L. (2000). Self-determination theory and the facilitation of intrinsic motivation, social development, and well-being. American Psychologist, 55(1), 68-78. https:// doi.org/10.1037/0003-066X.55.1.68

Ryan, R. M., \& Deci, E. L. (2020). Intrinsic and extrinsic motivation from a self-determination theory perspective: Definitions, theory, practices, and future directions. Contemporary Educational Psychology, 61, 101860. https://doi.org/10.1016/j.cedpsych.2020.101860

Sailer, M., \& Homner, L. (2020) The gamification of learning: A meta-analysis. Educational Psychology Review, 32, 77-112. https://doi.org/10.1007/s10648-019-09498-w

Seaborn, K., \& Fels, D. I. (2015). Gamification in theory and action: A survey. International Journal of Human-Computer Studies, 74, 14-31. https://doi.org/10.1016/j.ijhcs.2014.09.006

Sumonte Rojas, V., Friz Carrillo, M., Sanhueza, S., \& Morales Mendoza, K. (2019). Programa de integración lingüística y cultural: Migración no hispanoparlante [Linguistic and cultural integration program: Non-Spanish-speaking migration]. ALPHA: Revista de Artes, Letras y Filosofía, 1(48), 179-193. https://doi.org/10.32735/S0718-2201201900048625

Sumonte, V. (2020). Desarrollo de la competencia comunicativa intercultural en un programa de adquisición de la lengua Criollo Haitiana en Chile [Development of intercultural communicative competence in a Haitian Creole language acquisition program in Chile]. Íkala, Revista de Languaje y Cultura, 24(1), 155-169. https://doi.org/10.17533/udea.ikala.v25n01a09

Surendeleg, G., Murwa, V., Yun, H-K., \& Sang Kim, Y. (2014). The role of gamification in Education: A literature review. Contemporary Engineering Sciences, 7(29), 1609-1616. http://dx.doi.org/10.12988/ces.2014.411217

Swacha, J. (2021). State of research on gamification in education: A bibliometric survey. Education Sciences, 11(2), 69. https:/ / doi.org/10.3390/educsci11020069

Tan, M., \& Hew, K. F. (2016). Incorporating meaningful gamification in a blended learning research methods class: Examining student learning, engagement, and affective outcomes. Australasian Journal of Educational Technology, 32(5), 19-34. https://doi.org/10.14742/ajet.2232

United Nations Organization (UNO). (2019). Migration. http://www.un.org/es/sections/issues-depth/migration/index.html

Vygotsky, L. S. (1997). The collected works of L. S. Vygotsky. Volume 1: Thinking and speaking. Plenum Press. 
Wiggins, B. E. (2016). An overview and study on the use of games, simulations, and gamification in higher education. International Journal of Game-Based Learning, 6(1), 18-29. http:// doi.org/10.4018/IJGBL.2016010102

Wink, J., \& Putney, L. (2002). A vision of Vygotsky. Allyn \& Bacon. 